\title{
Environmental Determinants of Disease Prevalence in Rural Western Nepal
}

\author{
Uttam Paudel ${ }^{1 *}$, Krishna Prasad Pant ${ }^{2}$ \\ ${ }^{1}$ Environmental Health Economist, Tribhuvan University, Kathmandu, Nepal \\ ${ }^{2}$ Environmental Economist, Kathmandu University, Kathmandu, Nepal \\ Email: *uuupaudel22@gmail.com
}

How to cite this paper: Paudel, U. and Pant, K.P. (2018) Environmental Determinants of Disease Prevalence in Rural Western Nepal. Journal of Environmental Protection, 9, 1221-1236. https://doi.org/10.4236/jep.2018.912077

Received: September 15, 2018

Accepted: November 9, 2018

Published: November 12, 2018

Copyright (C) 2018 by authors and Scientific Research Publishing Inc. This work is licensed under the Creative Commons Attribution International License (CC BY 4.0).

http://creativecommons.org/licenses/by/4.0/ (c) (i) Open Access

\begin{abstract}
Environmental determinants causing unexpected disease rampant are seemed major challenges to be protective from inevitable hazards and to deal the future consequences in terms of human health loss. This paper explores the major environmental determinants stimulating disease prevalence in western hilly areas of Nepal. Cross-sectional analytical research design for household level primary data was treated with the binary logit regression model to identify the determinants of disease prevalence. Extreme winter temperature, decreasing winter rainfall, sporadic rain, drying spout and decreasing the tree species are the major environmental determinants; hand washing, proper management of solid waste from kitchen and habit of drinking boiled water are as household behavioral determinants; and adequate family members, higher education, use of pesticide to control the insects and use of clean cooking fuels are socioeconomic determinants encouraging disease prevalence. Plantation of large perennial and medicinal plants, proper management of warm clothes or heaters especially for old people and children having respiratory problems for extreme winter; management of water tank for long drought in winter and community awareness campaign for the protection of spout are urgent needs for the prevention of current disease prevalence. Ergo, the recommendations are made accordingly.
\end{abstract}

\section{Keywords}

Western Nepal, Disease Prevalence, Logit Model, Environmental Change

\section{Introduction}

Almost one third of global diseases can be directly related to environmental risk factors owing to poor access to sanitation and safe water supply, the potential 
cause of infection-forming conditions, mainly in the developing countries [1]. Therefore, environmental health science needs enough inputs from meteorologists, chemists, biologists, geologists and health economist to explore robust interdisciplinary findings of global environmental changes [2]. A study argued that South East Asia could face disastrous consequences due to climate change if not apply measures that can mitigate the effects by focusing on advanced knowledge and training; and by developing collaborative work [3]. However, some recent efforts commenced by the relevant government agencies seem to be less effective in stopping further environmental quality deterioration, because the actions taken are weakly coordinated and poorly integrated especially to implement laws regarding the threat to human security in terms of value [4] [5] [6] [7].

Environmental change plays an important role in controlling ecosystem variability and potential for outbreaks of several new diseases following deaths and morbidity associated with extreme and erratic weather in Nepal [8] [9] [10]. Nepal is one of the most vulnerable countries due to environmental changes including climate change and household characteristics. Vulnerability depends upon not only the environmental exposure [11] but also the household daily behaviors including economic aspects. A study [12] based on central part of Nepal claimed that namely central and western parts of Nepal are the most vulnerable for the climatic effects, giving way out for designing site-specific intervention strategies to apply mitigation measure.

The remarkable differences in natural environmental conditions are primarily related to an enormous range of elevation within a short north-south distance. Therefore, it is important to identify and analyze the environmental determinants controlling household behavioral determinants; where environmental indicators include climate change and other issues that associate with human health. A clear picture of the association between environmental change and the sudden outbreak of diseases may help to identify the total cost incurred at present and can predict the future consequences possibly concocted by exogenous natural hazards. Moreover, household level mitigation measures for the health effects of climate change may also be potential guidance for risky region all around the world.

Several outbreaks of malaria, Kala-azar, and Japanese encephalitis in the countryside of Nepal seem to be allied with changes in temperature [13]. More specifically, Jajarkot is one of the poorest and remotest districts of Nepal. Access to drinking water is estimated to be 49.4 percent of total households, ignoring the quality of available water to be further investigated. Access to sanitation is less than 22 percent, compared to the national average of 46 percent [14]. Open defecation is a common phenomenon and the lack of safe drinking water and hygienic practices make communities more vulnerable. This shows an alarming trend of climate change impact on human health and wellbeing.

Diarrhea is one of the leading causes of morbidity and mortality among children under five in Nepal, with 10,500 dying every year. Since some years before, every year in monsoon season, Jajarkot district and other districts in its 
surrounding belonging to the western region of Nepal has been suffering more often from high disease occurrence. Nepal government has also been there at the time of high prevalence of the diseases (Cholera and Diarrhea) and has spent a lot of money which might have the alternative use for welfare generation if there were no such seasonal events. This single example may lead to such many events in the country if we focused only on curative aspects, ignoring the impacts of other exogenous effects.

Some districts in the hilly region of Nepal have similar socio economic characteristics such as remoteness, lack of access to facility, low level of education, low Human Development Index (HDI), and poor health facilities among others but Jajarkot and other nearby districts are facing a high rate of new and old disease outbreaks every year. This is an unreached area of the researchers as well as an urgent information required to save a gigantic societal cost and for having an economically prosperous society. Therefore, Jajarkot is chosen as a potential study area to yield diseases and environment related primary information.

Scanty literatures based on Nepal are devoted only on the effects of climate on agriculture and other sectors but few literatures [15] [16] [17] are mainly devoted on exploring trend of disease occurrence in Nepal. Of the few literatures, none of the literature is found addressing whether environmental factors would be significant predictors of the disease prevalence or not. Moreover, indirect mitigation measures applied by the households to reduce the climatic effects on disease incidence are also unknown. Therefore, this research aims to identify factors influencing the disease prevalence in rural hilly areas of western Nepal.

\section{Materials and Methods}

Cross sectional analytical economic evaluation design has been employed using both primary and secondary data. National level data were collected from WHO, Epidemiology and Disease Control Division, Ministry of Health and Population, Department of Health, United Nation Children's Fund and Center for Disease Control, Central Department of Environmental Science and other concerning agencies working in disease interventions.

\subsection{Study Area}

The study areas are three wards of Bheri Municipality of Jajarkot district, as identified as high disease prevalence area and the place of the poorest in the mid-western region of Nepal. The study area (red colored area in Figure 1) is announced by the government as the area with extreme poverty and high disease afflicted. The district has 30 Village Development Committees. Darim Lek (5440 $\mathrm{m}$ ) is the highest altitude and $610 \mathrm{~m}$ is the lowest altitude within the district. The climate of the district ranges from subtropical to the alpine condition. Hilly and mountainous region of Nepal are claimed to be more climate sensitive areas where there is evidence of having new seasonal diseases unknowingly. Every year incidence of new viral diseases and other diseases have been occurring to dare the health challenge among people living in this area, death tolled already more 


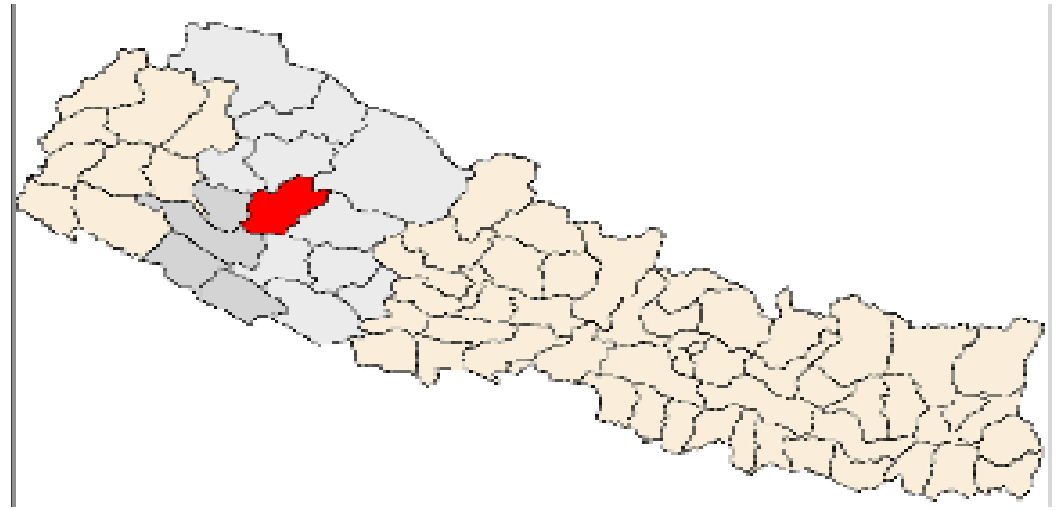

Figure 1. Study area (red color) of Nepal.

than 150 and more than 20,000 people are affected [15]. Study based on Jajarkot district can be representative to the hilly and mountainous region of western Nepal, and ultimately the study can cover the hilly rural region having high disease prevalence. Therefore, Jajarkor is selected for the potential informative area to obtain a valid association between environmental change and disease prevalence.

\subsection{Study Setting}

This study is by nature based on the disease prevalence due to environmental indicators changed over the last 15 years. The key informants of the research are household heads of age above 35 years. Therefore, a household based semi-structured questionnaire was developed for data collection. Both qualitative and quantitative response related questions were set in questionnaire balancing the flow of questions. The questionnaire incorporated both climatic and household behavioral related quires including the cost incurred by households for the treatment of the particular disease as well as task for mitigation of effect of climate change. Initially, a pilot survey was conducted for finding the area sensitive to the sudden disease outbreaks with the help of District Public Health Office of Jajarkot. After the completion of pilot survey conducted in the districts, Bheri municipality, one of the most affected area was selected based on the high disease occurrence with heterogeneity in the population.

\subsection{Sampling Technique and Sample Size}

Rapid assessment type of study was carried out before the application of sampling strategy and developing the data collection tools to understand the local situation and dimensions. This assessment first opened the avenues to carry out the research from different perspective. After the identification of affected Wards of Bheri Municipality of Jajarkot, a sampling frame was prepared from the list of households available in the office of the municipality. Different disease faced households list of the last 5 years was obtained from local health centers. With the help of this information, a simple random sampling method was applied in the selection of sample households. Therefore, samples from three 
Wards of the municipality which have been affected from diseases many often, where households are highly scattered and place of extreme poverty was selected by simple random sampling method. This gives a total of 200 households as the sample size for this study.

\subsection{Data Collection and Management}

Data were collected with the help of semi-structured pretested questionnaire containing both qualitative and quantitative aspects. Record reviews, and in-depth interviews with health professionals and community people were the fundamental techniques for data collection. First, questionnaire was pre-tested in Kavre district, then the required corrections were made based on the problem in pre-testing. Then, the questionnaire was finalized as per the suggestions of experts. Then, four enumerators were selected and trained them with ethical issues. So far the logistics were prepared to move towards the field from March 10 to 22, 2018. A field supervisor monitored the information collected and confirmed the information accuracy. Collected data were entered into the data entry software SPSS and transformed into STATA for the analysis.

Three sets of variables (environmental, socioeconomic and behavioral) that can affect the disease prevalence are prudently hypothesized with their expected sign. In addition, a general descriptive analysis is also presented in Table 1.

Table 1. Description of hypothesized variables.

\begin{tabular}{|c|c|c|c|c|}
\hline Variables & Definition & $\begin{array}{l}\text { Expected } \\
\text { sign }\end{array}$ & Mean & $\begin{array}{c}\text { Std. } \\
\text { Deviation }\end{array}$ \\
\hline $\begin{array}{c}\text { Winter temperature } \\
(\text { decrease }=1,0 \text { otherwise }))\end{array}$ & $\begin{array}{c}\text { Decreasing } \\
\text { winter temperature }\end{array}$ & + or - & 0.55 & 0.49 \\
\hline $\begin{array}{c}\text { Winter Rainfall } \\
\text { (decrease }=1,0 \text { otherwise) }\end{array}$ & $\begin{array}{l}\text { Decreasing } \\
\text { winter rainfall }\end{array}$ & + & 0.72 & 0.38 \\
\hline Sporadic rain $($ Yes $=1$, No $=0)$ & Untimely rain & + & 0.28 & 0.43 \\
\hline Cold waves $($ Yes $=1$, No $=0)$ & Feeling cold waves & + & 0.29 & 0.41 \\
\hline Thunderstorm $($ Yes $=1$, No $=0)$ & Having thunderstorm & + & 0.62 & 0.38 \\
\hline Drying spout $($ Yes $=1$, No $=0)$ & Spout is getting dried & + & 0.67 & 0.46 \\
\hline $\begin{array}{c}\text { Water animals } \\
\text { (Decrease }=1,0 \text { otherwise) }\end{array}$ & Decreasing water animals & + & 0.45 & 0.49 \\
\hline $\begin{array}{l}\text { Change in trees } \\
\text { (decrease }=1,0 \text { otherwise) }\end{array}$ & Decreasing trees & + & 0.72 & 0.45 \\
\hline $\begin{array}{c}\text { Hand wash } \\
\text { (soap }=1,0 \text { otherwise) }\end{array}$ & Hand washing with soap & - & 0.39 & 0.48 \\
\hline $\begin{array}{c}\text { Water preference } \\
\text { (Boiled }=1,0 \text { otherwise) }\end{array}$ & Boiled water preference & - & 0.23 & 0.33 \\
\hline $\begin{array}{c}\text { SW kitchen } \\
\text { (Inside }=1,0 \text { otherwie) }\end{array}$ & $\begin{array}{l}\text { Solid waste collection } \\
\text { inside kitchen }\end{array}$ & + & 0.73 & 0.24 \\
\hline Pesticide use $($ Yes $=1$, No $=0)$ & Use of pesticide to control pest & + & 0.69 & 0.30 \\
\hline Cooking fuel (wood $=1,0$ otherwise) & Wood as cooking fuel & + or - & 0.78 & 0.20 \\
\hline Family size & Number of household members & + & 6.83 & 3.33 \\
\hline Education (Years of Schooling) & Education of household head & - & 3.67 & 4.48 \\
\hline Total health expenditure (USD) & Household direct health cost & + & 685.95 & 1065.26 \\
\hline
\end{tabular}




\subsection{Econometric Modelling}

This research covers the impact of environmental change on disease prevalence across rural Nepal as far the data availability. Initially, to understand the impact of environmental change on the diseases, an unknown functional relationship is considered as,

$$
\boldsymbol{Q}=f(\boldsymbol{E}, \boldsymbol{X})
$$

Relation (1) links vectors of environmental variables $(E)$ and household behavioral variables $(\boldsymbol{X})$ to outcomes (disease prevalence $Q$ ). Vector $\boldsymbol{E}$ includes knowledge and perception about environmental change, natural disasters due to environmental change; and change in air, water resources and biodiversity (see Table 1). Similarly, $\boldsymbol{X}$ includes household characteristics that are not correlated with $E$, but affect $Q$, possibly by conditioning the environmental response. The vector $\boldsymbol{X}$ typically includes several controls also. The vector $\boldsymbol{X}$ also includes other exogenous geographic controls, such as elevation and ruggedness.

A classical approach to estimating (1) emphasizes spatial variation at a point in time. A linearized version of the above model is:

$$
Q=\alpha+\beta \boldsymbol{E}+\gamma \boldsymbol{X}+\varepsilon
$$

Here, disease prevalence is the dependent variable, which is binary in nature: high prevalence $=1$, less prevalence $=0$. Disease prevalence is identified by definition as the number of patients at home divided by family size. So, binary logit model is used to find the probable environmental effects on human health after controlling household differences. Other categorical independent variables are the dummy. The specific form of the binary logit regression model including all the hypothesized variables described in Table 1 is;

Disease prevalence $=\beta_{0}+\beta_{1}$ Winter Temperature $+\beta_{2}$ Winter Rainfall

$+\beta_{3}$ Sporadic Rain $+\beta_{4}$ Cold Wave $+\beta_{5}$ Thunderstorm

$+\beta_{6}$ Drying Spout $+\beta_{7}$ Water Animals $+\beta_{8}$ Changing Trees

$+\beta_{9}$ Hand Wash $+\beta_{10}$ Water Preference $+\beta_{11} \mathrm{SW}$ Kitchen

$+\beta_{12}$ Pesticide Use $+\beta_{13}$ Cooking Fuel $+\beta_{14}$ Family Size

$+\beta_{15}$ Education $+\beta_{16}$ Total health Expenditure

\section{Results}

\subsection{Results of Descriptive Analysis}

About two-thirds of total respondents were male (see Figure 2). With the age of the household head ( $\mathrm{HH}$ head) in the study, the mean age of the HH head is 45.96, covering least age of 35 up to 74 among the respondents as shown in Table 2. The average family size of the respondents is found 6.8 (see Table 2) which is quite higher than the national standard size 4.8 obtained from the population census 2011 [14].

Almost $96 \%$ of respondents were married because of the age requirement of respondent who were household head too. Most of the elderly people are illiterate or limited within primary education, while very less (12 respondents) people 


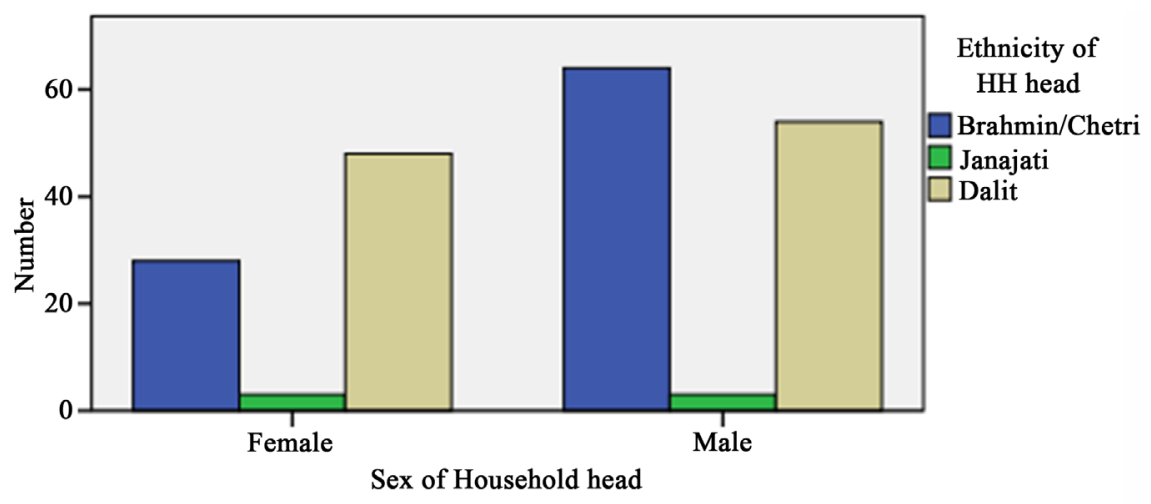

Figure 2. Ethnicity of household head by sex.

Table 2. Distribution of age, education and family size.

\begin{tabular}{ccccc}
\hline Description & Minimum & Maximum & Mean & Std. Deviation \\
\hline Age of HH head & 35 & 74 & 45.96 & 10.241 \\
Education of HH head & 0 & 14 & 3.67 & 4.483 \\
Family Size & 1 & 35 & 6.83 & 3.330 \\
\hline
\end{tabular}

(Note: Education 0: uneducated, Education 14: above bachelor's level).

are with intermediate level (grade 12) of education. Single respondent was available with higher education (above grade 12). The average education of household head seemed quite low as grade 4 completion in the study area (see Table 2).

Agriculture seems dominant occupation as almost $63 \%$ of the total households are reliant to this $0.81 \%$ of the total households have their own land for cultivation, ranging from 1 to 320 ropanies ( 20 ropanies $=1$ hectare) with mean 20 ropanies (CI: 16.04 - 25.13). Pipeline and river water are the major sources of drinking water for $92 \%$ of households. Only wood and LPG gas are the main cooking fuels covering $78 \%$ and $22 \%$ of total households respectively. Regarding lighting sources, solar covers $97 \%$ of households in the region and $3 \%$ of households belonging to this area have nothing for lighting. Besides agriculture, remittance basically from India is also the next potential source of income in the region.

Based on the survey data, almost $92 \%$ of the households have now felt increasing summer and winter temperatures compared to 15 years ago as shown in Table 3. But rainfall in monsoon and winter has reduced which might be a significant change in diseases emergence due to the livable environment for agents spreading disease.

Over $62 \%$ of total households listened about climate change mainly through radio and awareness program in Jajarkot. From those who listened about climate change (124 respondents), 119 responded for changing climate because of deforestation, natural reasons and overuse of resources in the region.

About $97.5 \%$ of households have afflicted of draught, thunderstorm, heat 
Table 3. Scenario of temperature and rainfall.

\begin{tabular}{cccc}
\hline \multirow{2}{*}{ Climatic Indices } & \multicolumn{3}{c}{ Response Summary (Percentage) } \\
\cline { 2 - 4 } & Increase & Decrease & No change \\
\hline Summer temperature & 92 & 1.5 & 6.5 \\
Winter temperature & 34 & 55 & 11 \\
Monsoon rainfall & 5.5 & 87 & 7.5 \\
Winter rainfall & 8.5 & 82.5 & 9 \\
\hline
\end{tabular}

waves, cold waves, diseases and landslide as potential effects of climate change in the western hilly Nepal, mainly because of low or heavy rain, deforestation, increased population and road construction. Thunderstorm, landslide and diseases seem major cause to increase the loss of property in the study areas. Without any doubts, two-thirds households have felt increasing trend of sickness in their families.

Basically, Diarrhea, Asthma, Pneumonia, Typhoid, Stone, Diabetes, Cholera and gastritis, heart diseases, malnutrition and uric acid are rampant in the study area. Recently appeared new diseases in the study area are Filariasis, Appendicitis, heart diseases, diabetes, pneumonia, diarrhea, jaundice and stone are the newly prevailing diseases in Jajarkot district of western Nepal. Malaria and Japanese Encephalitis seemed appeared at low land of western hilly regions. Similarly, diarrhea, typhoid, jaundice and cholera found commonly increasing in the study areas. Joint aches, abdominal cramps, diarrhea and vomiting are common in the study area regarding the water borne diseases.

Surprisingly, increasing pattern of movement of hot air in higher hilly areas of the study area is responded by $95 \%$ of the sample households. Regarding water resources, the amount of water in the rivers, ponds and wells has been continuously decreasing since 15 years before, might pose serious threat of environmental change owing to deforestation and over use of resources connected with decreasing water amount and quality in river. Regrettably, many small rivers in the region have already dried as well, $80 \%$ of households have seen dried river, $76 \%$ of them have already seen the dried spout which may produce a terrible drinking water scarcity in western Nepal.

A highest, $72 \%$ of respondents responded over decreasing trees in the area compared to 15 years before, $18.5 \%$ stands against the change and remaining 9.5\% are unknown about the change in the number of trees. Particularly, Shorea Robusta (Sal), Bombax (Simal), Ficus semichordata (Khanaye), Morus nigra (Kimbu) and Santalum albul (Vimal) trees are under the category of decreasing but Aegle marmelos (Bail) and Epilepil are the increasing tree whereas Simtara and $B$. variegate (Koiralo) are almost disappeared trees in the study area. Regarding the grass, Digiraria cruciata (Banso), Cynodon dactylon (Dubo) and Jaighas are declining but Thysanolaena maxima (Amrisho) and Raunna are the increasing species and, D. grandiflora (Lampate) and Khar have already disappeared. Cuscuta reflexa (Akashbeli) and Dante are the newly appeared plant 
species of shrub in the study areas. Moderately, few households (45\%) have responded in the favor of changed water animals. Fish, frog, crab and snakes are decreasing continuously in the river and no single water animals are getting increased, disappeared and newly appeared in the study areas. Owing to possibly unwitting the value of medicinal plant and non-timber forest, $O$. sanctum (tulasi), Barberis aristata (chutro), Persea glamblei (kaulo), Acorus calamus (Bojho), Centella asiatica (ghottapre), Cinnamomum tamala (Sinkauli), Azadirachta indica (neem), Ocimum basilicum (babari), Mentha arvensis (Pudina), and Zanthoxylum armantum (timur) are the species of medicinal plants getting decreased.

\subsection{Econometric Analysis: Determinants of Diseases Prevalence}

Regarding the determinants of disease prevalence in Jajarkot, few environmental variables, household behavior and some socioeconomic variables seem potentially significant (see Table 4) in the binary logistic regression run. All the significant variables in Table 4 are logically explained to draw an inference on disease control policy.

With family size, households with larger family size are less likely facing the diseases prevalence in the study areas. Though large family size would have enough caretaker for the capacity to control the disease at home from different dimension with their varieties of knowledge. So that these households might be less likely to have the probability chance of disease occurrence again. Increasing

Table 4. Results of econometric analysis. Dependent variable: Disease prevalence.

\begin{tabular}{|c|c|c|}
\hline Variable Name & Coefficients & Standard Error \\
\hline Decreasing winter temperature & $1.485^{\star *}$ & 0.582 \\
\hline Decreasing winter rain & $0.631^{\star *}$ & 0.687 \\
\hline Untimely rain & $1.661^{\star *}$ & 0.634 \\
\hline Cold waves & -0.631 & 0.687 \\
\hline Thunderstorm & 0.912 & 0.656 \\
\hline Drying spout & $1.417^{\star * *}$ & 0.580 \\
\hline Decreasing water animals & 0.259 & 0.635 \\
\hline Decreasing tree & $-1.206^{\star}$ & 0.661 \\
\hline Hand washing with soap & $0.9870^{*}$ & 0.563 \\
\hline Boiled water preferences & $-2.169^{* * *}$ & 0.841 \\
\hline Place of solid waste collection & $1.638^{\star}$ & 1.016 \\
\hline Pesticide use at home & $-1.382^{\star}$ & 0.834 \\
\hline Wood as cooking fuel & $4.847^{\star *}$ & 2.105 \\
\hline Family size & $-1.581^{\star * \star}$ & 0.255 \\
\hline Education level & $-0.121^{\star *}$ & 0.063 \\
\hline Total expenditure on health care & $-1.20 \mathrm{e}-06$ & $2.01 \mathrm{e}-06$ \\
\hline
\end{tabular}

${ }^{* * *} \mathrm{p}<0.01,{ }^{* *} \mathrm{p}<0.05,{ }^{*} \mathrm{p}<0.1, \mathrm{R}$-squared $=0.6$. 
the education level restricts the high prevalence of diseases in the study area. Education seems negatively significant to the high prevalence of disease. This might be obvious that education provides the knowledge to the person about the personal or social activities that may discourage the disease occurrence. Similarly, educated persons can prevent others not to be involved in activities concerning high chance of diseases occurrence.

Households using wood as the cooking fuel are more likely to have the diseases, compared to the household using clean fuels. Households using boiled drinking water are less likely to have diseases in comparison to the household using non-boiled water. Probably, the boiled water in the high disease prevalence areas will keep them safe from the entrance of waterborne diseases. So that the disease prevalence will be reduced in the high disease prevalence areas. Households collecting kitchen solid waste inside the kitchen are more likely to have the high prevalence of diseases in comparison to the waste collecting outside the kitchen. There might be possibility of transferring the waste from the collection to the prepared food in the kitchen by house flies or other insects, which might lead to food borne diseases.

Another potential well known cause of disease prevalence is hand washing habit before and after the meal. Here, regular well washing hands with soap before and after the meal is seemed less likely to have probability chance of disease prevalence in the high prevalence areas in comparison to those washing hands with water only. For the prevention from different insects and diseases, households seem using pesticides to avoid the chance of getting ill. Households using pesticide are less likely to have the disease occurrence in comparison to the households not using it. Prescribed pesticide for the household use seems more effective to better control of disease rampant in the community.

Regarding environmental variables, few environmental potential expected variables: decreasing winter temperature, decreasing winter rainfall, untimely rain, drying spout and decreasing trees around the community seemed significant to influence disease prevalence but the addition of the other environmental variables seemed insignificant but potential for the increase of explaining capacity of explanatory variables. Extreme cold winter temperature seems more likely to support the high disease prevalence in comparison to the warm winter temperature prevailing areas. Cold winter might be hazardous for respiratory diseases. Decreasing winter rainfall is also positively associated with the probability chance of increasing disease prevalence. It has been commonly known that rainfall reduces air pollution and water contamination which are the major source of human diseases. In the study area, most of the households have responded the current decrease in tree in their surrounding and in forest. Result in this research also reveals that decreasing the trees is linked with probability chance of high disease prevalence in the community (see Table 4).

Some dried and remaining drying spouts are also positively associated with disease rampant in the study area. Other environmental variables: thunderstorm, cold waves and total health inaction cost of household in the high disease preva- 
lence areas seem potential to cause in simple ordinary least square regression with being less explanatory but insignificant to describe the likelihood of disease occurrence chance. The inclusion of these variables in the model has increased the explanatory capacity of significant variables. This model is fit at with R-squared 0.60 as shown in Table 4.

\section{Discussions}

Prior to the discussion of the results, some pitfalls of this paper are to be reconnoitered. Firstly, this paper has overlooked some environmental components such as toxic pollutants. This paper has not included the health cost and benefit of the community people induced by environmental degradation, probably the potential objective of forth coming issue. Similarly, this paper is centered for the information of one district of Nepal, most affected by disease prevalence. Though this study is not free from some downsides, this study has been able to explore the determinants of disease prevalence in similar areas in western Nepal.

Among environmental determinants, cold winter temperature, decreasing winter rainfall, decreasing trees, sporadic rain and drying spout are significant determinants in the study areas which cover most of the environmental factors (see Table 4). Extreme cold winter may lead to decrease in body temperature of human being. Accordingly, extreme fall of winter temperature may be a favorable situation for the prevalence of some disease: Asthma [18], cold diarrhea [19] and Pneumonia. Winter rainfall is essential for the cultivation and environmental balance in hilly areas. Lack of winter rainfall increases the length of draught and degree of dryness. This situation leads to the air and water contamination which might ultimately result increasing Rotavirus activities [20] and exacerbation of chronic cardiac and pulmonary condition [21]. Similarly, sporadic rain seems one of the potential environmental factor to cause human disease. This irregular rainfall may accelerate the vector activity of malaria and other communicable diseases which might increase the disease occurrence [22] [23] [24].

Besides, this might be unquestionable that trees in the surrounding promote better human health from different dimensions. This result is consistent with two studies [25] [26] explaining high biodiversity including plants reduces the human diseases by the reduction of pathogen transmission. More dried spout results more likely to have probability chance of easy disease spread, meaning that spout protection program is an urgent need in the study areas. This result is parallel with some national evidences [27] [28] and international literature [29] [30] [31].

Household Size, education, hand washing habit, cooking fuel, boiled drinking water, use of pesticides and place of kitchen waste collection are also significant in the category of socioeconomic and household behavioral potential factors to influence the high prevalence of diseases. Regarding family size, larger household size seemed likely to reduce the disease occurrence. This result is opposite with some studies [32] [33] [34] but it is commonsensical to say that many 
members in family might have human resource to maintain in timely feeding and caretaking of fragile situation of health at home, and will be able to limit the disease under a mild state. Because of poverty and easy access in developing countries, firewood is dominant for cooking fuel in hilly areas [35], popularly known as a source of smoke increases the respiratory diseases [36]. Collection of kitchen waste inside the kitchen is harmful to human health. Air contamination through smell and reach of decayed waste to food might be the supporter of disease occurrence at home.

The growing incidences of water pollution, land and soil pollution, solid and hazardous waste pollution, deforestation, soil erosion are common examples of environmental quality decline because of unwanted human activities. Sanitation and hygiene promotion are the most cost-effective public health interventions. The simple act of hand-washing with soap can reduce the risk of diarrheal disease by 45 per cent [16]. Though the importance of Water, Sanitation and Hygiene (WASH) is recognized by the health sector in Nepal, the curative aspects of health promotion or technology-driven water and sanitation interventions often overshadow basic awareness and preventative measures. Evidences show that environmental changes bring many kinds of natural disasters incidence of vector-borne and waterborne disease in health sector and in crops and livestock [37] [38].

Concerning with biodiversity, some trees such as Sal, Simal, Khanaye, Kimbu and Vimal trees are under the category of decreasing but Bail and Epilepil the increasing trees and Simtara and Koiralo are almost disappeared. Similarly some grass and medicinal plants are also endangered which might be the alarming stage for biodiversity protection concerns. As per the people in the favor of change, tulasi, chutro, kaulo, ghottapre, tejpatta, neem, babari, and timur are the species of medicinal plants getting decreased. These plants upholds a gigantic value for the local medicines at household level that resist disease severity, and allow rural patients survive from possible health hazards. Therefore, environmentalist, health workers and policy makers are to be aware about the decreasing environmental quality and its consequences on human health.

\section{Conclusions}

This paper has developed a framework probably for first time finding the overall determinants of disease prevalence in rural western Nepal, popularly known for the highest diseases prevailing area in Nepal. The recent epidemiology information of western hilly districts of Nepal also indicates that there may occur continuous outbreak and rampant; therefore, this paper explored factors causing the diseases. Proper management of clothes and subsidized heat producing devices for extreme winter temperature, concept of water reservation tank for long or deficient winter rainfall, knowledge of being protected from sporadic rain, plantation of big and long lived trees and medicinal plants in the community campaign for biodiversity conservation, and protection of drying spout by the com- 
munity are seemed urgent which are strong determinants associated with human health. Similarly, at household level, environmental and health education to the household head, encouraging drinking only boiled water, washing hand with soap before and after meal, use of clean cooking fuel, collection of kitchen solid waste outside the kitchen are the most important factors to be positively taken into account for the control of disease prevalence. If such activities are currently overlooked, a gigantic health burden of poor household increasing impoverishment and catastrophe in western Nepal could be further exacerbated and the society might get highly vulnerable and unlivable. Therefore, Nepal Government along with other global cohorts has to set the national adaptation programs campaigns and policies being referenced with this result to protect western Nepal from disease rampant attributing to environmental dilapidation.

\section{Acknowledgements}

The authors acknowledge comments and suggestions for Faculty of Tribhuvan Univesity; Umesh Khatri and BimalaBaral, Co-worker in Research; and University Grants Commission Nepal.

\section{Funding Information}

This research paper has prepared without any external funding source.

\section{Author's Contributions}

Uttam Paudel prepared the manuscript. Krishna Prasad Pant revised the manuscript and both the authors finalized and approved the manuscript.

\section{Conflicts of Interest}

The authors declare that there is no any conflict of interest.

\section{References}

[1] World Health Organization (2009) Global Health Risks: Mortality and Burden of Disease Attributable to Selected Major Risks. World Health Organization, 87, 646-646.

[2] Paudel, U. (2018) A Review of Effects of Environmental Change on Human Health. American Journal of Environment Science, 14, 95-109. https://doi.org/10.3844/ajessp.2018.95.109

[3] Kumaresan, J., Narain, J.P. and Sathiakumar, N. (2011) Climate Change and Health in South East Asia. International Journal of Climate Change Strategies and Management, 3, 200-208. https://doi.org/10.1108/17568691111129020

[4] Malik, A., Grohmann, E. and Akhtar, R. (2014) Environmental Deterioration and Human: Natural and Anthropogenic Determinants. Springer, Berlin. https://doi.org/10.1007/978-94-007-7890-0

[5] World Health Organization (2014) Strengthening Health Resilience to Climate Change. World Health Organization, Geneva, 24-28.

[6] Mendelsohn, R. and Olmstead, S. (2009) The Economic Valuation of Environmen- 
tal Amenities and Disamenities: Methods and Applications. Annual Review of Environment and Resources, 34, 325-347.

https://doi.org/10.1146/annurev-environ-011509-135201

[7] Kumar, V., Mangal, A., Panesar, S., Yadav, G., Talwar, R., Raut, D., et al. (2014) Forecasting Malaria Cases Using Climatic Factors in Delhi, India: a Time Series Analysis. Malaria Research and Treatment, 14, 82-85.

[8] McMichael, A.J. (2013) Globalization, Climate Change, and Human Health. The New England Journal of Medicine, 368, 1335-1343. https://doi.org/10.1056/NEJMra1109341

[9] Dhimal, M., Ahrens, B. and Kuch, U. (2015) Climate Change and Spatiotemporal Distributions of Vector-Borne Diseases in Nepal-A Systematic Synthesis of Literature. PLOS ONE, 10, 23-32. https://doi.org/10.1371/journal.pone.0129869

[10] Central Beaurau of Statistics (2016) National Climate Change Impact Survey 2016. CBS, Kathmandu.

[11] McDowell, G., Ford, J.D., Lehner, B., Berrang-Ford, L. and Sherpa, A. (2013) Climate-Related Hydrological Change and Human Vulnerability in Remote Mountain Regions: A Case Study from Khumbu, Nepal. Regional Environmental Change, 13, 299-310. https://doi.org/10.1007/s10113-012-0333-2

[12] Panthi, J., Aryal, S., Dahal, P., Bhandari, P., Krakauer, N.Y. and Pandey, V.P. (2016) Livelihood Vulnerability Approach to Assessing Climate Change Impacts on Mixed Agro-Livestock Smallholders around the Gandaki River Basin in Nepal. Regional Environmental Change, 16, 1121-1132. https://doi.org/10.1007/s10113-015-0833-y

[13] Dahal, S. (2008) Climatic Determinants of Malaria and Kala-Azar in Nepal. Reg. Heal. Forum, 12, 32-37.

[14] CBS (2012) National Population and Housing Census 2011 (National Report). Gov. Nepal, Natl. Plan. Comm. Secr. Cent. Bureau Stat., 1, 1-278.

[15] Nepal Health Research Council (2007) National Workshop on Climate Change and Human Health: Potential Impact, Vulnerability and Adaptation in Nepal. Journal of Nepal Health Research Council, 1-117.

[16] Bhandari, G.P., Dixit, S.M. and Ghimire, U.M. (2009) Outbreak Investigation of Diarrheal Diseases in Jajarkot. Journal of Nepal Health Research Council, 7, 66-68.

[17] Pant, D., Tenzin, T., Chand, R., Sharma, B. and Bist, P. (2017) Spatio-Temporal Epidemiology of Japanese Encephalitis in Nepal, 2007-2015. PLoS One, 12, e0180591. https://doi.org/10.1371/journal.pone.0180591

[18] Hijioka, Y., Lin, E., Pereira, J.J., Corlett, R.T., Cui, X., Insarov, G.E., Lasco, R.D., Lindgren, E. and Surjan, A. (2014) Asia. In: Barros, V.R., Field, C.B., Dokken, D.J., Mastrandrea, M.D., Mach, K.J., Bilir, T.E., Chatterjee, M., Ebi, K.L., Estrada, Y.O., Genova, R.C., Girma, B., Kissel, E.S., Levy, A.N., MacCracken, S., Mastrandrea, P.R. and White, L.L., Eds., Climate Change 2014: Impacts, Adaptation, and Vulnerability. Part B: Regional Aspects. Contribution of Working Group II to the Fifth Assessment Report of the Intergovernmental Panel on Climate Change, Cambridge University Press, Cambridge, 1327-1370.

[19] Gamble, J.L., Ebi, K.L., Sussman F.G., Wilbanks, T.J., Reid, C., Thomas, J.V., Weaver, C.P., Harris, M. and Freed, R. (2008) Executive Summary. In: Analyses of the Effects of Global Change on Human Health and Welfare and Human Systems, A Report by the U.S. Climate Change Science Program and the Subcommittee on Global Change Research, U.S. Environmental Protection Agency, Washington DC, $1-11$.

[20] Atchison, C., Iturriza-Gómara, M., Tam, C. and Lopman, B. (2010) Spatiotemporal 
Dynamics of Rotavirus Disease in Europe. The Pediatric Infectious Disease Journal, 29, 1. https://doi.org/10.1097/INF.0b013e3181d06fcd

[21] Centers for Disease Control (2004) Respiratory Syncytial Virus Activity-United States, 2003-2004. Morbidity and Mortality Weekly Report, 53, 1159-1160.

[22] Badu, M. (2012) Assessing the Impact of Climate Change on Human Health: Status and Trends of Malaria and Diarrhea with Respect to Temperature and Rainfall Variability in Nepal. Katandu Univ. J. Sci. Technol., 8, 134-141.

[23] Viorel-Ilie, A., Corina, A., Ozunu, A., Nour, E., Roşian, G. and Muntean, L.O. (2011) The Relation between the Landslide Activity and Irregular Rainfall and Snowmelt in the Codrului Hills, Romania. Environmental Engineering and Management Journal, 10, 3-6. https://doi.org/10.30638/eemj.2011.001

[24] Rozendaal, J.A. (1992) Relations between Anopheles Darlingi Breeding Habitats, Rainfall, River Level and Malaria Transmission Rates in the Rain Forest of Suriname. Medical and Veterinary Entomology, 6, 16-22. https://doi.org/10.1111/j.1365-2915.1992.tb00029.x

[25] Young, H.S., Wood, C.L., Kilpatrick, A.M., Lafferty, K.D., Nunn, C.L. and Vincent. J.R. (2017) Conservation, Biodiversity and Infectious Disease: Scientific Evidence and Policy Implications. Philosophical Transactions of the Royal Society B: Biological Sciences, 372, Article ID: 20160124. https://doi.org/10.1098/rstb.2016.0124

[26] Ostfeld, R.S. (2017) Biodiversity Loss and the Ecology of Infectious Disease. The Lancet Planetary Health, 1, e2-e3. https://doi.org/10.1016/S2542-5196(17)30010-4

[27] Mishra, S.R., Bhandari, P.M., Issa, R., Neupane, D., Gurung, S. and Khanal, V. (2015) Climate Change and Adverse Health Events: Community Perceptions from the Tanahu District of Nepal. Environmental Research Letters, 10, Article ID: 034007. https://doi.org/10.1088/1748-9326/10/3/034007

[28] Asian Development Bank (2013) Country Environment Note-Nepal. Asian Development Bank, Mandaluyong.

[29] Bowen, K.J. and Ebi, K.L. (2017) Health Risks of Climate Change in the World Health Organization South-East Asia Region. WHO South-East Asia Journal of Public Health, 6, 4-9. https://doi.org/10.4103/2224-3151.213789

[30] World Health Organization (2017). WHO South-East Asia Report. World Health Organization, 6, 1-98.

[31] World Health Organization (2016) Protecting Surface Water for Health-Identifying, Assessing, and Managing Drinking-Water Quality Risks in Surface-Water Catchments. World Health Organization, Geneva, 196.

[32] Joshi, P.C., Kaushal, S., Aribam, B.S., Khattri, P., D’Aoust, O., Singh, M.M., et al. (2011) Recurrent Floods and Prevalence of Diarrhea among under Five Children: Observations from Bahraich District, Uttar Pradesh, India. Global Health Action, 4, 1-8. https://doi.org/10.3402/gha.v4i0.6355

[33] Oriakhi, H.O., Onemolease, E.A., Health, N., Scheme, I. and State, E. (2012) Determinants of Rural Household's Willingness to Participate in Community Based Health Insurance Scheme in Edo State, Nigeria. Studies on Ethno-Medicine, 6, 95-102. https://doi.org/10.1080/09735070.2012.11886425

[34] Hajat, S., Vardoulakis, S., Heaviside, C. and Eggen, B. (2014) Climate Change Effects on Human Health: Projections of Temperature-Related Mortality for the UK during the 2020s, 2050s and 2080s. Journal of Epidemiology and Community Health, 68, 641-648. https://doi.org/10.1136/jech-2013-202449

[35] Paudel, U., Khatri, U. and Pant, K.P. (2018) Understanding the Determinants of 
Household Cooking Fuel Choice in Afghanistan: A Multinomial Logit Estimation. Energy, 156, 55-62. https://doi.org/10.1016/j.energy.2018.05.085

[36] Pant, K.P. (2012) Cheaper Fuel and Higher Health Costs among the Poor in Rural Nepal. Ambio, 41, 271-283.

[37] Food and Agriculture Organization (2009) The State of Food and Agriculture 2009: Livestock in the Balance. FAO, Rome.

[38] Hunter, P.R. (2003) Climate Change and Waterborne and Vector-Borne Disease. Journal of Applied Microbiology, 94, 37-46.

https://doi.org/10.1046/j.1365-2672.94.s1.5.x 